\title{
Expression of microRNA-23b in patients with sepsis and its effect on leukocytes and the expression of E-selectin and ICAM-1
}

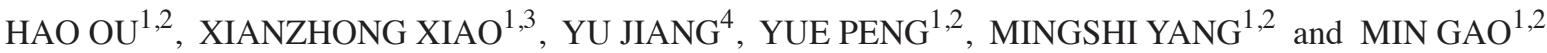 \\ ${ }^{1}$ Translational Medicine Center of Sepsis; ${ }^{2}$ Department of Critical Care Medicine, The Third Xiangya Hospital \\ of Central South University, Changsha, Hunan 410013; ${ }^{3}$ Department of Pathophysiology, Xiangya School \\ of Medicine, Central South University, Changsha, Hunan 410078; ${ }^{4}$ Hunan Provincial Institute \\ of Emergency Medicine, Hunan Provincial People's Hospital, Changsha, Hunan 410005, P.R. China
}

Received April 2, 2018; Accepted September 10, 2018

DOI: $10.3892 /$ etm.2018.6759

\begin{abstract}
The expression of microRNA-23b in peripheral blood leukocytes of patients with sepsis was investigated to assess the correlations with leukocyte, E-selectin, ICAM-1 and disease severity. The expression of microRNA-23b in peripheral blood leukocytes from 87 patients with sepsis, 50 patients with systemic inflammatory response syndrome (SIRS) and 50 normal controls were measured by reverse transcription-quantitative PCR (RT-qPCR), and stability of microRNA-23b was evaluated. Enzyme-linked immunosorbent assay (ELISA) was used to detect E-selectin and ICAM-1. Sequential organ failure assessment (SOFA) scoring system was used to assess the severity of sepsis patients. Correlation analysis was performed between microRNA-23b and the total number of white blood cells (WBC), E-selectin, ICAM-1, and SOFA scores. Compared with the normal control group, the expression level of microRNA-23b in the sepsis group was significantly decreased $(\mathrm{P}<0.05)$, and $\mathrm{WBC}$ and $\mathrm{E}$-selectin were significantly increased $(\mathrm{P}<0.05)$. ICAM-1 level in the sepsis and the SIRS groups was significantly higher than that in the control group $(\mathrm{P}<0.05)$, and it is also higher in the sepsis group than in the SIRS group. In the sepsis group, the expression level of microRNA-23b in the death group was significantly lower than that in the survivor group $(\mathrm{P}<0.05)$, while the level of E-selectin, ICAM-1, and SOFA scores were significantly higher in the death group than in the survivor group $(\mathrm{P}<0.05)$, while there was no significant difference in WBC between the groups $(\mathrm{P}>0.05)$. The expression level of microRNA-23b in patients with sepsis was significantly negatively correlated with SOFA scores, E-selectin, and ICAM-1 ( $\mathrm{r}=-0.633$, -0.585 , and -0.439 , respectively, $\mathrm{P}<0.05)$. The expression of microRNA-23b in peripheral blood of patients with sepsis is
\end{abstract}

Correspondence to: Dr Min Gao, Translational Medicine Center of Sepsis, The Third Xiangya Hospital of Central South University, 138 Tongzipo Road, Changsha, Hunan 410013, P.R. China E-mail: m6rqfv@163.com

Key words: microRNA-23b, sepsis, leukocyte, E-selectin, ICAM-1 related to the manifestation of the inflammatory state, and can be used to judge the severity and prognosis of patients with this disease.

\section{Introduction}

Sepsis as a systemic inflammatory response syndrome (SIRS) caused by an infection can cause damage to the body tissues and organs themselves and can even be life-threatening (1). Various stress reactions lead to inflammatory reactions, within which the binding of leukocytes to vascular endothelial cells induces immune response through cytokines, selectins (such as E-selectin), and accessory factor (such as ICAM-1) (2). Sepsis is a common cause of death in ICU critically ill patients, and in those cases sepsis is usually caused by different degrees of infection after major surgery, severe trauma, burns and shock (3). At present, the incidence of sepsis is approximately $0.3 \%$ and the mortality rate is $20-40 \%$ (4). The pathophysiology of sepsis is still unclear, combined with limited clinical means, leading to a poor prognosis in patients with sepsis.

MicroRNAs have the function of post-transcriptional regulation and play an important role in many processes such as secretory metabolism, inflammatory reactions, and tumor formation (5). Recent studies have revealed that microRNA-23b can affect cell proliferation, differentiation, apoptosis, and cell-to-tissue adhesion (6). In addition, studies have suggested that microRNA-23b can prevent autoimmune diseases (7). Inhibition of the microRNA-23b expression in tumor tissue can inhibit the proliferation of tumor cells to a certain extent (8). MicroRNA can be detected in various types of body fluids and has high stability (9). Therefore, microRNAs are generally used as a marker for early disease diagnosis and prognosis assessment (10). In this study, the expression of microRNA-23b in peripheral blood of patients with sepsis was observed to investigate its correlation with levels of leukocytes, E-selectin and ICAM-1 levels as well as the severity of disease.

\section{Patients and methods}

General information. A total of 87 patients with sepsis was selected from September 2015 to December 2017 in The Third 
Xiangya Hospital of Central South University (Changsha, China). All patients met the diagnostic criteria of sepsis (11). In addition, 50 patients with SIRS and 50 normal health people were included to serve as controls. Patients who met 2 of the following 4 criteria were diagnosed as SIRS: i) heart rate $>90$ beats/min; ii) respiratory rate $>20$ beats/min; iii) total number of white blood cells (WBC) $<4.0 \times 10^{9} / 1$ or $>12 \times 10^{9} / \mathrm{l}$; iv) body temperature $>38^{\circ} \mathrm{C}$ or $<36^{\circ} \mathrm{C}$. Mean age of subjects in the sepsis, the SIRS, and the control groups was $55.8 \pm 17.6$ years, $58.6 \pm 15.1$ years and $53.8 \pm 17.2$ years, respectively. There were 60 males and 27 females in the sepsis group, 35 males and 15 females in the SIRS group, and 36 males and 14 females in the control group. There was no statistical difference in age and sex among the three groups. All participants or family members signed an informed consent. The study was approved by the Ethics Committee of the Third Xiangya Hospital of Central South University.

Major reagents and instruments. TRIzol RNA extraction kit (Sangon Biotech Co., Ltd., Shanghai, China), cDNA synthesis kit (Sangon Biotech Co., Ltd.), RT-qPCR kit (Takara Bio, Inc., Otsu, Japan), E-Selectin and ICAM-1 enzymelinked immunosorbent assay kits (Sangon Biotech Co., Ltd.). Nucleic acid quantitative detector (Thermo Fisher Scientific, Inc., Waltham, MA, USA), fluorescence quantitative PCR instrument (ABI, Foster City, CA, USA). All primers were synthesized by GenScript Co., Ltd. (Nanjing, China).

Observation of clinical indicators. Age, sex, primary disease, and arterial blood gas analysis, inhaled oxygen concentration, WBC, mean arterial pressure, platelet count, hemoglobin, blood creatinine, urine volume and GCS within $24 \mathrm{~h}$ after onset of patients in the sepsis group were recorded. The worst-case values of physiological parameters of these indicators and actual test results were subjected to sequential organ failure assessment (SOFA) scoring system (12). Outcomes (survival or death) at 30 days after onset were recorded.

Reverse transcription-quantitative PCR (RT-qPCR) to detect the expression of microRNA-23b. After diagnosis, venous blood was collected from patients in the morning. Blood was centrifuged at $2,100 \mathrm{xg}$ at $4^{\circ} \mathrm{C}$ for $10 \mathrm{~min}$ to collect serum. Serum samples were stored at $-20^{\circ} \mathrm{C}$ before use. TRIzol kit was used to extract total RNA from peripheral blood, and nucleic acid quantification detector was used to measure RNA concentration. cDNA was synthesized using cDNA synthesis kit. With U6 as endogenous control, the expression of microRNA-23b was detected by RT-qPCR. PCR reaction system consisted of $10 \mu \mathrm{l}$ of SYBR-Green Master Mix, $0.5 \mu \mathrm{l}$ of upstream and downstream primers, $1 \mu \mathrm{l}$ of cDNA, and $8 \mu \mathrm{l}$ of $\mathrm{ddH}_{2} \mathrm{O}$. Reaction conditions were: $95^{\circ} \mathrm{C}$ for $3 \mathrm{~min}$, followed by 40 cycles of $95^{\circ} \mathrm{C}$ for $30 \mathrm{sec}$ and $58^{\circ} \mathrm{C}$ for $1 \mathrm{~min}$. Sequences of primers used in PCR reactions were: 5'-TCTCCCTGGCGTCCTCCCTTCG-3' (forward) and 5'-CC TTATCAAGAACACCAACCAGT-3' (reverse) for microRNA-23b; 5'-CTCGCTTCGGCAGCACA-3' (forward) and 5'-AACGCTTCACGAATTTGCGT-3' (reverse) for U6.

MicroRNA-23b stability testing. Peripheral blood collected from 5 participants of each group was kept as $4^{\circ} \mathrm{C}$, and

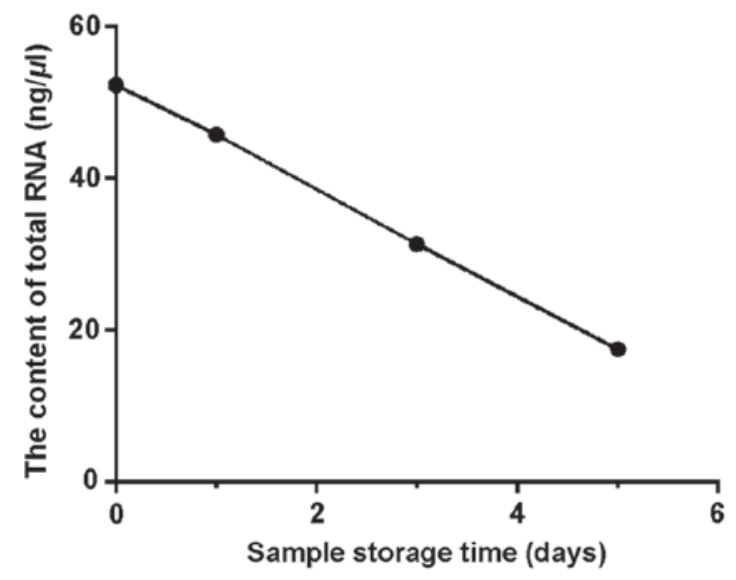

Figure 1. Changes of total RNA concentration in peripheral blood leukocytes over time. Total RNA concentration was detected by a nucleic acid quantification detector. Results showed that total RNA concentration decreased continuously after $0,1,3$, and 5 days of storage at $4^{\circ} \mathrm{C}$.

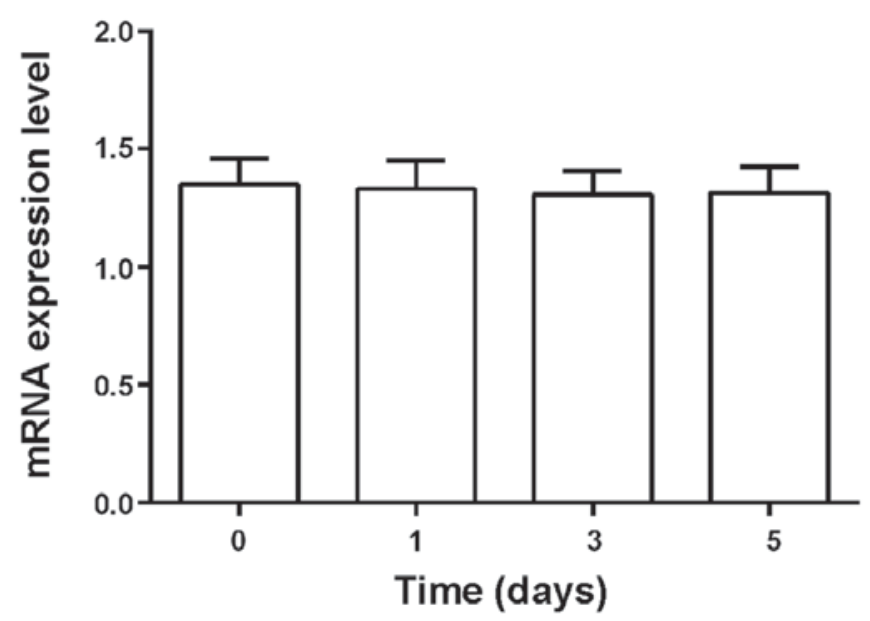

Figure 2. Changes in levels of microRNA-23b in peripheral blood leukocytes over time. Results of RT-qPCR showed that there were no significant changes in the levels of microRNA-23b after storage at $4^{\circ} \mathrm{C}$ for $0,1,3$, and 5 days.

samples were collected at day $0,1,3$, and 5 respectively. Total RNA was extracted and RNA concentration was detected by a nucleic acid quantitative detector. Finally, RT-qPCR was performed to detect the expression of microRNA-23b and assess its stability.

Enzyme-linked immunosorbent assay (ELISA) to detect E-selectin and ICAM-1. Peripheral blood of each group (sepsis group and SIRS collected within $24 \mathrm{~h}$ ) was collected and centrifuged at $1,680 \mathrm{xg}$ at $4^{\circ} \mathrm{C}$ for $20 \mathrm{~min}$. Serum was separated and serum E-selectin and ICAM-1 levels were determined by ELISA according to the instructions of the kit.

Statistical analysis. SPSS 17.0 (SPSS Inc., Chicago, IL, USA) was used for statistical analysis. Measurement data were expressed as mean \pm standard deviation. Variance analysis was used for analysis among multiple groups and the post hoc test was Least Significant Difference test. t-test was used for comparison between two groups. Chi-square test was to compare enumeration data. Correlation analysis 
Table I. Comparison of basic clinical data among groups.

\begin{tabular}{|c|c|c|c|c|c|}
\hline Clinical data & Control & SIRS & Sepsis & $\mathrm{F}\left(\chi^{2}\right)$ & P-value \\
\hline Age (years) & $58.3 \pm 6.8$ & $60.8 \pm 8.7$ & $62.4 \pm 6.8$ & 0.229 & 0.802 \\
\hline $\begin{array}{l}\text { Sex (cases) } \\
\text { Male } \\
\text { Female }\end{array}$ & $\begin{array}{l}36 \\
14\end{array}$ & $\begin{array}{l}35 \\
15\end{array}$ & $\begin{array}{l}60 \\
27\end{array}$ & 0.139 & 0.933 \\
\hline WBC $\left(10^{9} / 1\right)$ & $6.15 \pm 1.22$ & $12.13 \pm 2.83^{\mathrm{a}}$ & $12.98 \pm 3.61^{\mathrm{a}}$ & 6.578 & 0.031 \\
\hline Mean arterial pressure $(\mathrm{mmHg})$ & $78.6 \pm 7.0$ & $52.75 \pm 6.75^{\mathrm{a}}$ & $53.25 \pm 7.35^{\mathrm{a}}$ & 14.32 & 0.005 \\
\hline $\mathrm{CRP}(\mathrm{mg} / \mathrm{l})$ & $8.8 \pm 1.02$ & $78.3 \pm 5.05^{\mathrm{a}}$ & $77.3 \pm 6.43^{\mathrm{a}}$ & 96.235 & $<0.001$ \\
\hline $\mathrm{PCT}(\mu \mathrm{g} / \mathrm{l})$ & $0.32 \pm 0.2$ & $9.3 \pm 1.8^{\mathrm{a}}$ & $11.9 \pm 1.5^{\mathrm{a}}$ & 60.514 & $<0.001$ \\
\hline Blood lactate $(\mathrm{mmol} / \mathrm{l})$ & $2.0 \pm 0.5$ & $4.5 \pm 0.8^{\mathrm{a}}$ & $4.7 \pm 0.6^{\mathrm{a}}$ & 16.296 & 0.004 \\
\hline
\end{tabular}

${ }^{\text {a }}<<0.05$, compared with the control group. SIRS, systemic inflammatory response syndrome; WBC, white blood cells.

Table II. Comparison of levels of microRNA-23b, WBC, E selectin and ICAM-1 in peripheral blood among groups.

\begin{tabular}{|c|c|c|c|c|c|}
\hline Groups & No. of cases & MicroRNA-23b & WBC $\left(10^{9} / 1\right)$ & E-selectin $(\mathrm{ng} / \mathrm{ml})$ & ICAM-1 (ng/ml) \\
\hline Control & 50 & $1.08 \pm 0.28$ & $6.15 \pm 1.22$ & $51.82 \pm 11.86$ & $296.37 \pm 31.58$ \\
\hline SIRS & 50 & $0.21 \pm 0.07^{\mathrm{a}}$ & $12.98 \pm 2.83^{\mathrm{a}}$ & $129.44 \pm 41.32^{\mathrm{a}}$ & $367.39 \pm 50.15^{\mathrm{a}}$ \\
\hline Sepsis & 87 & $0.16 \pm 0.03^{\mathrm{a}}$ & $12.13 \pm 3.61^{\mathrm{a}}$ & $138.35 \pm 38.28^{\mathrm{a}}$ & $559.83 \pm 53.36^{\mathrm{a}, \mathrm{b}}$ \\
\hline F-value & & 28.607 & 5.535 & 5.863 & 25.662 \\
\hline $\mathrm{P}$-value & & 0.001 & 0.043 & 0.039 & $<0.001$ \\
\hline
\end{tabular}

${ }^{\mathrm{a}} \mathrm{P}<0.05$, compared with the control group; ${ }^{\mathrm{b}} \mathrm{P}<0.05$, compared with the SIRS group. WBC, white blood cells; SIRS, systemic inflammatory response syndrome.

Table III. Comparison of microRNA-23b, E-selectin, ICAM-1, WBC and SOFA scores between the survivor and death groups in the sepsis group.

\begin{tabular}{lccccc}
\hline Groups & No. of cases & MicroRNA-23b & E-selectin & ICAM-1 & WBC \\
\hline Survivor group & 71 & $0.18 \pm 0.04$ & $112.4 \pm 21.7$ & $370.25 \pm 43.92$ & $12.03 \pm 2.15$ \\
Death group & 16 & $0.05 \pm 0.02$ & $150.4 \pm 27.3$ & $612.33 \pm 87.52$ & $12.08 \pm 2.13$ \\
t value & & 11.258 & -11.753 & -9.625 & -19.875 \\
P-value & & 0.008 & 0.007 & 0.011 & -10.392 \\
\hline
\end{tabular}

WBC, white blood cells; SOFA, sequential organ failure assessment.

was performed using Pearson's correlation analysis. $\mathrm{P}<0.05$ was considered to indicate a statistically significant difference.

\section{Results}

MicroRNA-23b stability analysis. Total RNA concentration decreased from 52.3 to $17.5 \mathrm{ng} / \mu \mathrm{l}$ after 5 days of storage at $4^{\circ} \mathrm{C}$, indicating that total RNA in peripheral blood samples will be gradually degraded over time (Fig. 1). However, there was no significant change in levels of microRNA-23b and endogenous control U6 in blood samples after storage for $0,1,3$, and 5 days at $4^{\circ} \mathrm{C}$ (Fig. 2).
Comparison of basic clinical data among groups. Significant differences were found in WBC, mean arterial pressure, CRP, PCT and blood lactate levels when comparing the SIRS group or the sepsis group with the control group $(\mathrm{P}<0.05)$. There was no significant difference in these factors between the SIRS and the sepsis groups $(\mathrm{P}>0.05)$. There was no significant difference in age and sex among the three groups $(\mathrm{P}>0.05)$ (Table I).

Comparison of levels of microRNA-23b, WBC, E-selectin and ICAM-1 in peripheral blood among groups. As shown in Table II, the expression level of microRNA-23b in the sepsis and the SIRS groups was significantly lower than that in the control group $(\mathrm{P}<0.01)$, while the WBC, E-selectin, and 
Table IV. Correlation analysis between microRNA-23b, WBC, E-selectin, ICAM-1, and SOFA scores.

\begin{tabular}{lrrrrr}
\hline & \multicolumn{2}{c}{ MicroRNA-23b } & & \multicolumn{2}{c}{ SOFA } \\
\cline { 2 - 3 } \cline { 6 - 6 } Items & \multicolumn{1}{c}{$r$} & P-value & & $\mathrm{r}$ & P-value \\
\hline WBC & 0.103 & 0.082 & & 0.115 & 0.079 \\
E-selectin & -0.585 & 0.008 & & 0.206 & 0.065 \\
ICAM-1 & -0.439 & 0.008 & & 0.237 & 0.060 \\
SOFA & -0.633 & 0.007 & & & \\
\hline
\end{tabular}

WBC, white blood cells; SOFA, sequential organ failure assessment.

ICAM-1 levels were significantly increased in the sepsis and SIRS groups compared to the control group $(\mathrm{P}<0.05)$. ICAM- 1 level in the sepsis group was significantly higher than that in the SIRS group $(\mathrm{P}<0.05)$, but there was no significant difference in the microRNA-23b, WBC, and E-selectin between the sepsis and the SIRS groups $(\mathrm{P}>0.05)$.

Comparison of microRNA-23b, E-selectin, ICAM-1, WBC and SOFA scores between the survivor and the death groups in the sepsis group. Mortality rate in the sepsis group was $18.4 \%$ (16/87). The expression level of microRNA-23b in the death group was significantly lower than that in the survivor group $(\mathrm{P}<0.05)$, and the E-selectin, ICAM-1, and SOFA scores were significantly higher in the death group than in the survival group $(\mathrm{P}<0.05)$. There was no significant difference in WBC between the survival and the death groups (Table III).

Correlation analysis. The expression level of microRNA-23b in the sepsis group was significantly negatively correlated with SOFA score, serum E-selectin, and ICAM-1 $(r=-0.633,-0.585$, and -0.439 , respectively, $\mathrm{P}<0.05)$, but not $\mathrm{WBC}(\mathrm{P}>0.05)$. There was no significant correlation between WBC, E-selectin, ICAM-1 and SOFA scores $(\mathrm{P}>0.05)$ (Table IV).

\section{Discussion}

Most patients with sepsis have immune dysfunction. Release of inflammatory transmitters after infection can cause damage of vascular endothelial cells, which in turn increases vascular permeability, and further inducing the transition from SIRS to sepsis shock accompanied by multiple organ dysfunction (13). Early sepsis is easily misdiagnosed as SIRS, leading to delayed treatment. Therefore, more specific markers are required for the diagnosis of sepsis.

MicroRNAs are responsible for the regulation of gene expression and play an important role in the pathophysiology of many diseases (14). MicroRNA-125b, $-150,-223$, and -146 have been proven to play critical roles in pathogenesis of sepsis (15). MicroRNA-23b is a newly discovered microRNA, and studies have shown that peripheral blood levels of microRNA-23b can reflect the progression of gastric cancer. With the aggravation of gastric cancer, the expression level of microRNA-23b is increased (16). Studies have also shown that microRNA-23b is highly expressed in peripheral blood of patients with myasthenia gravis (17). Results of our study showed that the expression of microRNA-23b in the sepsis group was significantly lower than that in the normal control group $(\mathrm{P}<0.01)$, and the microRNA-23b expression level in the death group was significantly lower than that in the survivor group $(\mathrm{P}<0.05)$. The data suggest that the development of sepsis is accompanied by the downregulation of microRNA-23b. Furthermore, the microRNA-23b expression level was negatively correlated with SOFA score, suggesting that the expression of microRNA-23b is related to the severity and prognosis of the disease. However, there was no significant difference in the expression level of microRNA-23b between the sepsis and the SIRS groups, so microRNA-23b could not be used to distinguish between sepsis and SIRS.

E-selectin is present on the surface of activated vascular endothelial cells and can bind to leukocytes to promote the activation of vascular endothelial cells and mediates inflammatory responses (18). Nimrichter et al (19) found that E-selectin can enhance leukocyte aggregation, and Kung et al (20) suggested that E-selectin could be used as a marker for severe infections and bacteremia. Leukocyte aggregation along the vascular wall of lesion regions is a prerequisite for the adherence of WBC and endothelial cells and passing through blood vessel wall (21). ICAM-1 is an adhesion molecule with a very small molecular weight that promotes leukocyte adhesion and aggravates inflammatory damage (22). Studies have shown that ICAM-1 and E-selectin are increased in sepsis peripheral blood, and the content of those two factors in serum can be used to judge the extent of endothelial damage. Damage of endothelial cells indicates the development of inflammatory reaction (23). Results of our study showed that ICAM-1 level in the sepsis group was significantly higher than that in the control group $(\mathrm{P}<0.05)$, and ICAM-1 level in the sepsis group was significantly higher than that in the SIRS group $(\mathrm{P}<0.05)$. In addition, ICAM-1 level in the death group was significantly higher than that in the survivor group $(\mathrm{P}<0.05)$, suggesting that the level of ICAM-1 is related to the severity of sepsis. Bedirli et al (24) believed that ICAM-1 level is increased in early stages of sepsis, and high ICAM-1 predicts poor prognosis and high mortality. The levels of WBC and E-selectin were significantly higher in the sepsis group than in the control group, but there was no significant difference between the sepsis and SIRS groups $(\mathrm{P}>0.05)$, suggesting that WBC and E-selectin can only reflect the presence of inflammation, and cannot be used to distinguish between sepsis and SIRS. The levels of E-selectin and ICAM-1 in the death group were significantly higher than those in the survivor group, suggesting that E-selectin and ICAM-1 levels may be related to disease severity. E-selectin and ICAM-1 levels have no significant correlation with SOFA, indicating that E-selectin and ICAM-1 may not be promising diagnostic and prognostic markers for sepsis.

In conclusion, the expression level of microRNA-23b in peripheral blood of patients with sepsis is related to the manifestation of inflammatory state, and to some extent, it can be used to judge the severity and prognosis of disease.

\section{Acknowledgements}

Not applicable. 


\section{Funding}

The study was supported by the New Xiangya Talent Project of Xiangya Hospital of Central South University (JY201606).

\section{Availability of data and materials}

The datasets used and/or analyzed during the present study are available from the corresponding author on reasonable request.

\section{Authors' contributions}

HO drafted the manuscript. HO and XX contributed to RT-qPCR. YJ and YP contributed to microRNA-23b stability testing. HO, MY and MG were responsible for ELISA. All authors read and approved the final manuscript.

\section{Ethics approval and consent to participate}

The study was approved by the Ethics Committee of the Third Xiangya Hospital of Central South University (Changsha, China). Signed informed consents were obtained from the patients or guardians.

\section{Patient consent for publication}

Not applicable.

\section{Competing interests}

The authors declare that they have no competing interests.

\section{References}

1. Caserta S, Kern F, Cohen J, Drage S, Newbury SF and Llewelyn MJ: Circulating plasma microRNAs can differentiate human sepsis and systemic inflammatory response syndrome (SIRS). Sci Rep 6: 28006, 2016.

2. Santana H, Ítalo Sousa P, Marques LM, Figueiredo TB and Silva RAAD: Distinct strains of Staphylococcus aureus lead to different inflammatory response patterns in a murine model of intradermal infection. Acta Sci Biol Sci 38: 457-464, 2016.

3. Suresh PK, Minal J, Rao PS, Ballal K, Sridevi HB and Padyana M: Volume conductivity and scatter parameters as an indicator of acute bacterial infections by the automated haematology analyser. J Clin Diagn Res 10: EC01-EC03, 2016.

4. Moitra R, Beal DR, Belikoff BG and Remick DG: Presence of preexisting antibodies mediates survival in sepsis. Shock 37: $56-62,2012$

5. Behbahani GD, Ghahhari NM, Javidi MA, Molan AF, Feizi N and Babashah S: MicroRNA-mediated post-transcriptional regulation of epithelial to mesenchymal transition in cancer. Pathol Oncol Res 23: 1-12, 2017.

6. Fukumoto I, Koshizuka K, Hanazawa T, Kikkawa N, Matsushita R, Kurozumi A, Kato M, Okato A, Okamoto Y and Seki N: The tumor-suppressive microRNA-23b/27b cluster regulates the MET oncogene in oral squamous cell carcinoma. Int J Oncol 49: 1119-1129, 2016.

7. Goto Y, Kojima S, Nishikawa R, Enokida H, Chiyomaru T, Kinoshita T, Nakagawa M, Naya Y, Ichikawa T and Seki N: The microRNA-23b/27b/24-1 cluster is a disease progression marker and tumor suppressor in prostate cancer. Oncotarget 5: 7748-7759, 2014.
8. Chiyomaru T, Seki N, Inoguchi S, Ishihara T, Mataki H, Matsushita R, Goto Y, Nishikawa R, Tatarano S, Itesako T, et al: Dual regulation of receptor tyrosine kinase genes EGFR and c-Met by the tumor-suppressive microRNA-23b/27b cluster in bladder cancer. Int J Oncol 46: 487-496, 2015.

9. Enelund L, Nielsen LN and Cirera S: Evaluation of microRNA stability in plasma and serum from healthy dogs. Microrna 6: 42-52, 2017.

10. Nassar FJ, Nasr R and Talhouk R: MicroRNAs as biomarkers for early breast cancer diagnosis, prognosis and therapy prediction. Pharmacol Ther 172: 34-49, 2017.

11. Chvojka J and Matějovič M: International guidelines for management of severe sepsis and septic shock 2012 - comment. Vnitr Lek 60: 59-67, 2014 (In Czech).

12. Minne L, Abu-Hanna A and de Jonge E: Evaluation of SOFA-based models for predicting mortality in the ICU: A systematic review. Crit Care 12: R161, 2008.

13. Roderburg C, Luedde M, Vargas Cardenas D, Vucur M, Scholten D, Frey N, Koch A, Trautwein C, Tacke F and Luedde T: Circulating microRNA-150 serum levels predict survival in patients with critical illness and sepsis. PLoS One 8: e54612, 2013.

14. Hervé $M$ and Ibrahim EC: MicroRNA screening identifies a link between NOVA1 expression and a low level of IKAP in familial dysautonomia. Dis Model Mech 9: 899-909, 2016.

15. Cheng HS, Sivachandran N, Lau A, Boudreau E, Zhao JL, Baltimore D, Delgado-Olguin P, Cybulsky MI and Fish JE: MicroRNA-146 represses endothelial activation by inhibiting pro-inflammatory pathways. EMBO Mol Med 5: 1017-1034, 2013.

16. Zhou H, Guo JM, Lou YR, Zhang XJ, Zhong FD, Jiang Z, Cheng J and Xiao BX: Detection of circulating tumor cells in peripheral blood from patients with gastric cancer using microRNA as a marker. J Mol Med (Berl) 88: 709-717, 2010.

17. Barzago C, Lum J, Cavalcante P, Srinivasan KG, Faggiani E, Camera G, Bonanno S, Andreetta F, Antozzi C, Baggi F, et al: A novel infection- and inflammation-associated molecular signature in peripheral blood of myasthenia gravis patients. Immunobiology 221: 1227-1236, 2016.

18. Velázquez F, Grodecki-Pena A, Knapp A, Salvador AM, Nevers T, Croce K and Alcaide P: CD43 functions as an E-Selectin ligand for Th17 cells in vitro and is required for rolling on the vascular endothelium and Th17 cell recruitment during inflammation in vivo. J Immunol 196: 1305-1316, 2016.

19. Nimrichter L, Burdick MM, Aoki K, Laroy W, Fierro MA, Hudson SA, Von Seggern CE, Cotter RJ, Bochner BS, Tiemeyer M, et al: E-selectin receptors on human leukocytes. Blood 112: 3744-3752, 2008

20. Kung CT, Hsiao SY, Su CM, Tsai TC, Cheng HH, Tsai NW, Chang WN, Huang CR, Wang HC, Lin WC, et al: Serum adhesion molecules as predictors of bacteremia in adult severe sepsis patients at the emergency department. Clin Chim Acta 421: 116-120, 2013.

21. Cahill PA and Redmond EM: Vascular endothelium - Gatekeeper of vessel health. Atherosclerosis 248: 97-109, 2016.

22. Raffray L, Giry C, Thirapathi Y, Reboux AH, Jaffar-Bandjee MC and Gasque P: Increased levels of soluble forms of E-selectin and ICAM-1 adhesion molecules during human leptospirosis. PLoS One 12: e0180474, 2017.

23. Figueras-Aloy J, Gómez-López L, Rodríguez-Miguélez JM, Salvia-Roiges MD, Jordán-García I, Ferrer-Codina I, CarbonellEstrany X and Jiménez-González R: Serum soluble ICAM-1, VCAM-1, L-selectin, and P-selectin levels as markers of infection and their relation to clinical severity in neonatal sepsis. Am J Perinatol 24: 331-338, 2007.

24. Bedirli N, Demirtas CY, Akkaya T, Salman B, Alper M, Bedirli A and Pasaoglu H: Volatile anesthetic preconditioning attenuated sepsis induced lung inflammation. J Surg Res 178: e17-e23, 2012.

This work is licensed under a Creative Commons Attribution-NonCommercial-NoDerivatives 4.0 International (CC BY-NC-ND 4.0) License. 